7

SECCIÓN: Teorías geográficas, geografía de la cultura y la vida cotidiana
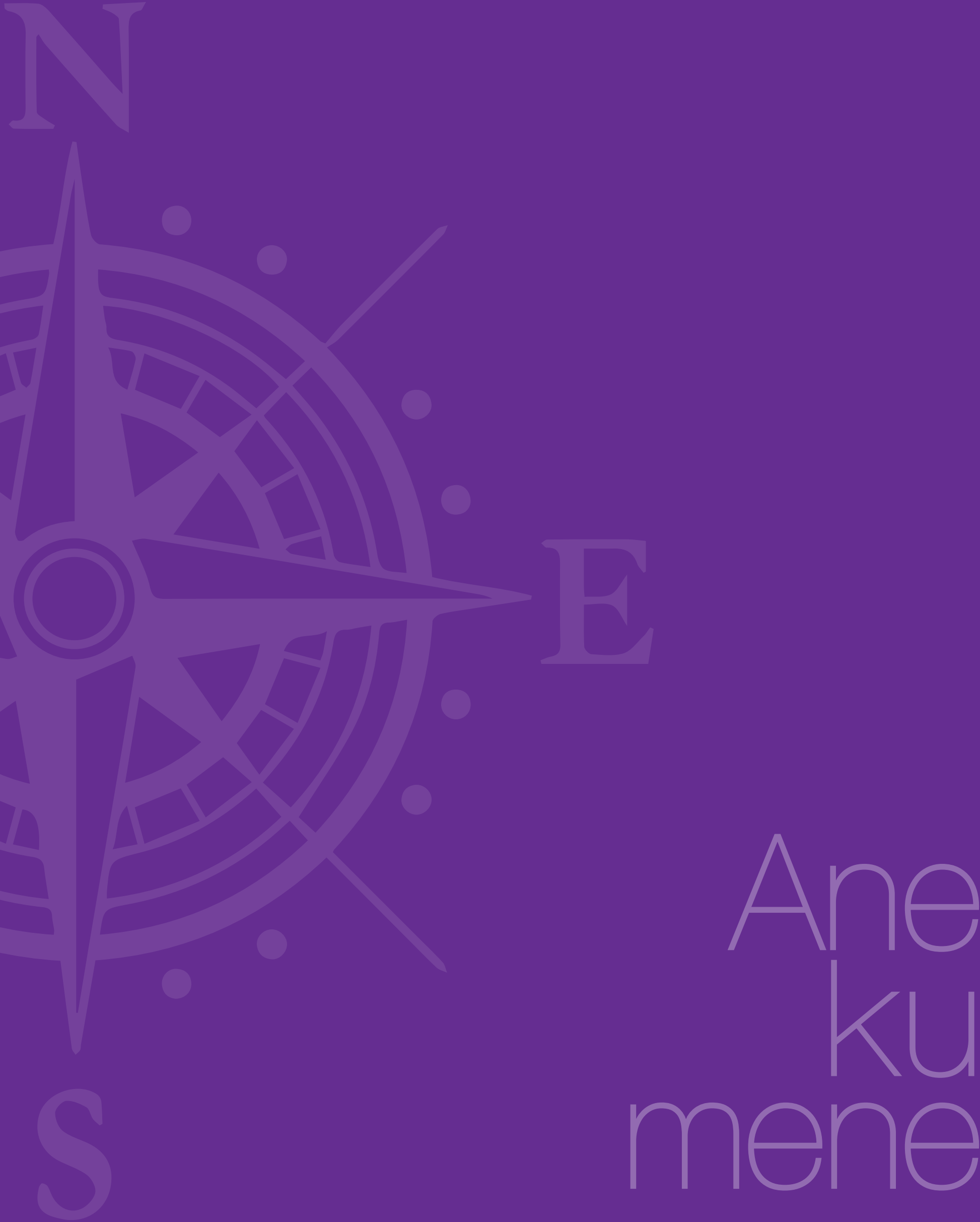


\section{Origem, permanência e significados das feiras livres no início do século XXI}

\section{Origin, Permanence and Meanings of Street Fairs in the} Early $2 \mathrm{I}^{\text {st }}$ Century

\section{Origen, permanencia y significados de los mercados populares al inicio del siglo XXI}

Gil Carlos Silveira Porto*

\begin{abstract}
Resumo
As feiras livres (ou mercados periódicos) continuam presentes na paisagem de muitas cidades brasileiras. Geralmente se espacializam em ruas, esquinas e praças, acontecem aos sábados e domingos e fazem parte das práticas sociais e da memória de muitos brasileiros. Neste artigo discuto diferentes dimensões desse fenômeno, buscando compreender o que as torna tão importantes para os moradores de cinco municípios situados no interior da Bahia/Brasil. As feiras resultam da necessidade de compra e venda dos agentes que as produzem, da organização temporal da sociedade local e das decisões individuais desses mesmos agentes. Além disso, tornam-se lugares de múltiplos significados onde são compartilhados projetos, alegrias, tristezas e acontecimentos da vida cotidiana. $O$ texto é parte de uma pesquisa concluída, cujos caminhos metodológicos se deram por meio da observação detalhada das feiras, da aplicação de questionário e do desenvolvimento de entrevistas com seus utentes.
\end{abstract}

\section{Palavras-chave}

Feiras livres; paisagem cultural; lugar; significados; Bahia. 


\begin{abstract}
Street fairs are still present in the landscape of many Brazilian cities. They are usually found in streets, corners, and squares, open on Saturdays and Sundays, and are part of the social practices and memory of many Brazilians. In this paper, I discuss different dimensions of this phenomenon, in an attempt to understand what makes them so important for the residents of five municipalities in Central Bahia, Brazil. Fairs are the result of a need to buy and sell products, the temporary organization of local society and individual decisions. In addition, they become places of multiple meanings where projects, joys, sorrows and events of daily life are shared. The text is part of a completed research, the methodology of which included the detailed observation of the fairs, the application of a questionnaire, and interviews with users.
\end{abstract}

\section{Resumen}

Los mercados siguen presentes en el paisaje de muchas ciudades brasileñas. Por lo general se encuentran en las calles, esquinas y plazas, suelen ocurrir los sábados y domingos y hacen parte de las prácticas sociales y de la memoria de muchos brasileños. En este artículo discuto diferentes dimensiones de ese fenómeno, buscando comprender lo que los hace tan importantes para los habitantes de cinco municipios ubicados en el interior de Bahía, Brasil. Los mercados son el resultado de la necesidad de compra y venta de los agentes que los producen, de la organización temporal de la sociedad local y de las decisiones individuales de esos mismos agentes. Además, se convierten en espacios de múltiples significados en donde se comparten proyectos, alegrías, tristezas y sucesos del cotidiano. El texto es parte de una investigación concluida, cuya metodología se basa en la observación detallada de los mercados, la aplicación de un cuestionario y el desarrollo de entrevistas con sus usuarios.

\section{Keywords}

Street fair; cultural landscape; place; meanings; Bahia.

\section{Palabras clave}

Mercados; paisaje cultural; lugar; significados; Bahía. 


\section{Considerações iniciais}

As feiras livres continuam presentes na paisagem de muitas cidades brasileiras. Geralmente se espacializam em ruas, esquinas e praças, acontecem aos sábados e domingos e fazem parte das práticas sociais e culturais da população. No entanto, mesmo com presença consolidada na dinâmica intraurbana, os pensadores do espaço geográfico deram pouca atenção a esse fenômeno no século passado. Seja pela necessidade de abordá-lo na Geografia, ou mesmo para desvelar o movimento da sociedade por meio delas, o fato é que os mercados periódicos têm lugar especial no cotidiano e na memória de muitos brasileiros e, por isso, merece nossa atenção investigativa.

Ao lançar o olhar sobre a feira livre e o conjunto de relações e redes que a sustentam, podemos compreendê-la em pelo menos três perspectivas. A primeira refere-se à sua natureza econômica, podendo ser enfatizada como uma das dimensões do circuito inferior ${ }^{1}$ da economia urbana (Porto, 2005, 2007), bem como a partir do sistema de trocas de produtos e mercadorias no qual se insere; uma segunda abordagem pode focar na morfologia desses espaços, onde se identificam seções de mercadorias. Essa perspectiva pode ser inserida numa geografia cultural e histórica desenvolvida, por exemplo, pelo geógrafo estadunidense Carl Sauer, para o qual a paisagem é um conjunto de formas naturais e culturais associadas em área, cujas materialidade e extensão são atributos essenciais (Corrêa, 2014, p.41). Uma terceira abordagem revela como a feira livre se insere na paisagem urbana como fenômeno cultural a partir dos significados que tem para seus usuários e dos vínculos construídos historicamente por eles, e pode ser analisada como evento que resulta das aspirações humanas.

O presente ensaio pretende dar conta desta última perspectiva, lançando o olhar geográfico sobre cinco feiras livres localizadas nos municípios de Maiquinique, Macarani, Itarantim, Itororó e Itapetinga (Figura 1), situados no Sudoeste da Bahia, Brasil. É parte de uma pesquisa de mestrado concluída, cujos caminhos metodológicos foram construídos a partir da observação detalhada dos mercados periódicos, da aplicação de

\section{Localização Das Feiras Livres Estudadas}
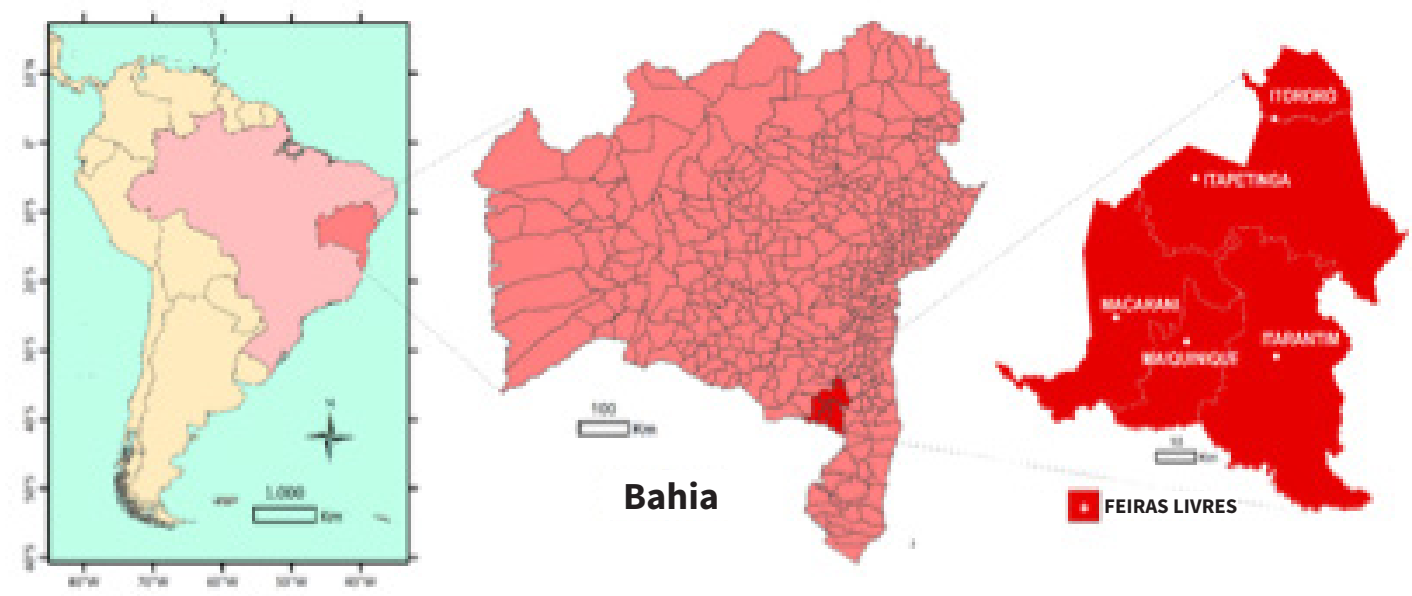

Figura 1. Mapas com as localizações das feiras.

1 Um dos circuitos da economia integrante da Teoria dos Dois Circuitos da Economia Urbana nos Países Subdesenvolvidos (Santos, 1979), cujas características presentes nas feiras livres, vão desde o desenvolvimento das atividades, que apresentam aspecto primitivo, passando pela maneira como o preço das mercadorias pode resultar da discussão entre comprador e vendedor, e chegando no quesito publicidade, que é nula tratando-se das atividades feirenses. 
questionário e do desenvolvimento de entrevistas com seus utentes, e as informações foram analisadas, também, a partir das entrelinhas ou do que não foi dito.

O interesse pelos mercados periódicos ampara-se na identificação de poucos estudos sobre esse fenômeno nas pesquisas geográficas, e a escolha especial pelas cidades mencionadas decorre do fato de conhecê-las e de uma delas (a feira livre de Maiquinque) fazer parte das práticas cotidianas pretéritas do autor deste artigo, quando nela comercializava produtos de origem rural, encontrava conhecidos e consumia produtos ali vendidos, às vezes no próprio espaço da feira, sob uma barraca de lona.

$\mathrm{Na}$ Antiguidade, quando o homem primitivo deixa de ser simplesmente coletor e passa a ser produtor de seus alimentos, começa a comercializar o excedente da produção nos embriões dos atuais mercados periódicos. Na Idade Média, os mercados periódicos perdem importância, uma vez que os grupos humanos se fixaram predominantemente no espaço rural. Na chamada "Era Moderna", os espaços livres de comercialização ganham novo significado e as cidades passam a ser lugares privilegiados para o comércio, sobretudo nas feiras livres. Chega-se então à contemporaneidade, na qual o capitalismo impulsiona o processo de urbanização e a atividade de compra e venda é transferida, na maioria das grandes cidades, para as grandes redes de supermercados.

Como o processo de mundialização econômica não chega a todos os lugares ao mesmo tempo e com a mesma intensidade, as mudanças pelas quais passam as feiras livres demoram a acontecer, principalmente em regiões onde os elementos que condicionam o modo de vida (a cultura, a relação com a terra, o meio físico) resistem a serem modificados. Nesse contexto, esses fenômenos continuam existindo na maioria das cidades do Brasil, mantendo grande relevância para as populações locais, especialmente em municípios da Região Nordeste, onde o capitalismo não conseguiu transformar antigas relações entre produtor, vendedor e consumidor.

Essas relações pretéritas referem-se a uma diversidade de combinações e fenômenos, que vão desde a forma como os homens utilizam-se do espaço e quais instrumentos servem de meio para essa apropriação, ao modo como se vende produtos na feira e as interações que se dão entre vendedores e consumidores. Também se aludem ao conjunto de práticas, de costumes e de valores que regem a relação do agricultor com a terra, ao tipo de ferramenta utilizada em seu trabalho e a interação dele com a comunidade na qual se insere. Essas relações permaneceram pouco alteradas em muitas áreas do Brasil e da América do Sul.

Desse modo, uma parcela dos produtos que abastece os mercados locais em muitas localidades continua sendo produzida por pequenos proprietários rurais e suas famílias que, como faziam seus antepassados, continuam desenvolvendo a agricultura de subsistência em locais geralmente próximos à área de comercialização, sem uso de agrotóxicos e máquinas.

\section{Identificando múltiplas dimensões das feiras livres}

O conhecimento científico produzido nas ciências humanas ainda continua marcado de racionalidade positivista, no entanto, passa-se a dar atenção a outras dimensões dos fenômenos espaciais. Atendendo às novas demandas desse início de século, torna-se cada vez mais necessária a valorização de diferentes abordagens investigativas, abordagens essas que valorizem a história, os sentimentos e as tradições dos grupos humanos que produzem espaço. Na Geografia, estudos que focam a produção e a organização do espaço a partir da cultura ou das sociedades que nele habitam têm crescido significativamente. No entanto, são raros os trabalhos que abordam as feiras livres e o que elas revelam sobre a cultura e o comportamento geográfico das comunidades onde se territorializam.

Bromley, Symansky e Good (1980) analisaram os mercados periódicos em diversos contextos têmporo-espaciais e reafirmaram a relação existente entre elas e a segregação socioespacial e as práticas de determinados grupos. Acreditam que as feiras geralmente surgem em sociedades estratificadas com nítidas divisões de trabalho e fortes vínculos de influências externas. Tornam-se periódicas a partir do estabelecimento do comércio em tempo parcial e a designação de dias especiais para a sua realização, e persistem no tempo pelas necessidades dos produtores e consumidores, da organização do tempo. Sobre esta dimensão temporal afirmam que "os agrupamentos de mercado periódico estão relacionados aos conceitos socioculturais de tempo, à duração da semana ou mês estabelecidos, e à existência de dias separados para descanso, cerimônias religiosas ou reuniões públicas e festividades" (Bromley, Symanski \& Good, 1980, p. 185).

Ainda de acordo com os autores acima mencionados, as feiras livres persistem no tempo em função das necessidades de produtores e consumidores, da organização do tempo, da inércia e da vantagem comparativa. A necessidade que o comerciante-feirante tem de vender seus produtos com o objetivo de adquirir o mínimo de dinheiro para manter o funcionamento do seu ponto de venda e para sua sobrevivência, bem como a primordialidade de compra dos consumidores, que não cultivam mais em suas propriedades determinados produtos ou porque migraram do campo para a cidade, constituem-se fatores indispensáveis na permanência dessas feiras. 
Um aspecto relevante a ser considerado nas feiras estudadas é o fato de que parte dos vendedores não se dedica apenas à atividade desenvolvida naqueles espaços. Cerca de $40 \%$ dos comerciantes entrevistados trabalham em outras atividades durante a semana e a comercialização de produtos na feira se constitui em possibilidade de aumentar a renda mensal. Esse fato ocasiona a existência de um comerciante com perfil diferente daqueles profissionais que vivem e sobrevivem apenas da atividade feirense.

Quanto à organização do tempo, pode-se afirmar que as feiras estudadas continuam a existir por causa da maneira como, historicamente, as populações locais apropriaram-se funcionalmente da sequência de dias e noites, organizando-os de forma a atender suas necessidades: dias para o trabalho, dias para o descanso e dias para as festividades. Nesse contexto, as respectivas comunidades locais escolheram um dia da semana para que a feira acontecesse, nesse caso o sábado. A escolha desse dia está ligada ao calendário das atividades semanais de cada município, historicamente definido.

No mundo ocidental, ao longo do tempo, dos sete dias semanais, os homens trabalham cinco, do segundo ao sexto dia, os demais, sábado e domingo, foram destinados ao lazer e ao descanso. $O$ fato de a maioria das feiras nordestinas acontecerem aos sábados e aos domingos e, no caso das feiras estudadas, acontecerem no sexto dia, indica que foram originadas não apenas para atender a necessidade de compra e de venda dos consumidores e comerciantes, mas também para servir de lazer, constituindo-se numa atividade festiva, onde seus participantes, ao irem à feira, pudessem conversar, socializando os fatos semanais ocorridos nas suas comunidades e reencontrar amigos e familiares. Ao acontecerem no mesmo dia da semana, os mercados revelam a importância que têm, sobretudo local, pois é a população de cada município que se torna o agente responsável pela aparição de cada um deles.

A inércia constitui um dos fatores citados por Bromley, Symansky e Good (1980) que possibilita a permanência das feiras nas sociedades contemporâneas. Ela se caracteriza por um conjunto de comportamentos ou atributos que continuam presentes nesses eventos, mesmo com as transformações ocorridas nas relações trabalhistas, de produção e de comércio. Ela se manifesta em diferentes atitudes de quem compra e de quem vende. $\mathrm{O}$ hábito de comprar no mercado periódico ao invés de adquirir os produtos em um supermercado ou mesmo deixar de vendê-los em boxes ${ }^{2}$ para comercializá-los na feira livre pode ser considerado uma manifestação da inércia.

O fato de $30 \%$ dos boxes do mercado da feira de Itapetinga permanecerem fechados, revela, dentre outras questões, a "escolha" que seus

2 Os boxes são partes dos mercados divididos por tipos de produtos comercializados. Já os mercados, neste caso, são estruturas físicas construídas ao lado das feiras livres ou que passaram a abrigá-las, em algumas cidades. "proprietários" fazem em comercializar seus produtos no espaço externo, ou seja, na feira livre, onde se aglomeram mais consumidores, produtos e as interações sociais são mais pujantes. Esse comportamento reflete também a permanência do costume de comprar nas feiras livres, o que possibilita a permanência das mesmas no tempo, que resistem em modificar os padrões tradicionais, padrões esses presentes no ato de vender o produto em uma barraca ou tabuleiro, até mesmo no chão, constituindo-se em elemento característico na produção e na configuração espacial delas.

Quanto à vantagem comparativa, Bromley, Symansky e Good (1980) afirmam que ela se constitui em um dos fatores que determina a permanência das feiras livres no espaço citadino. É possível que em muitas delas, situadas em localidades que não foram pesquisadas, esse comportamento esteja presente, auferindo maior centralidade em um grupo de feiras em detrimento de outro, porém as feiras objeto de reflexão aqui não apresentam vantagens que atraiam consumidores dos municípios vizinhos ou de regiões do entorno, ou seja, quase totalidade dos feirantes é do próprio município onde a feira ocorre.

Essa frágil influência externa permite afirmar que os mercados periódicos de Maiquinique, Macarani, Itarantim, Itororó e Itapetinga são centros locais, pois atendem, sobretudo, às populações que ali residem. Sendo assim, nenhuma delas apresenta vantagem comparativa em relação às outras. Portanto, o fato de continuarem existindo não deve ser associado a esse comportamento, mas ao fato de persistirem no tempo pela função social, econômica e pelo valor e significado que têm para àqueles que dela fazem uso.

Considerando a feira como fenômeno cultural e os significados que possui, cabe neste momento da escrita um questionamento: o que se entende por cultura? De acordo com o periódico Géographie et cultures (1992) (apud Corrêa, 1995, p. 2 e 3) cultura é o conjunto daquilo que é transmitido e inventado (técnicas, atitudes, valores e as condições de transmissão) e caracteriza-se por "componentes materiais, sociais, intelectuais e simbólicos". Para Sauer (1963) (apud Corrêa, 1995, p. 3) a cultura "origina-se, difunde-se e evolui no tempo e no espaço, sendo compreensível no tempo, porém traçável no espaço onde se localiza". Diante desses conceitos, a feira livre pode ser entendida como manifestação cultural, pois as relações que a sustentam são transmitidas de geração em geração, se torna visível na configuração urbana, é um produto da sociedade e possui conteúdo simbólico.

Cosgrove (1999, p. 105) afirma que há "culturas dominantes e subdominantes ou alternativas". Para ele, as culturas subdominantes que se expressam na paisagem podem ser divididas em: residuais (que sobram do passado), emergentes (que antecipam o futuro) e excluídas (que são ativa ou passivamente suprimidas). As feiras estudadas, assim como a maioria das feiras brasileiras, pelas características que apresentam, 
constituem uma paisagem residual no espaço das cidades. A presença e expansão de estabelecimentos formais (mercados e supermercados) nos arredores dessas feiras se configuram, como manifestação de uma cultura dominante, ao passo que as atividades feirenses são entendidas como cultura subdominante ou alternativa, uma cultura residual.

Segundo Claval (1995 apud Corrêa, 1995, p. 4 e 5) a paisagem é, de um lado, resultado de uma dada cultura e, de outro, constitui-se em uma matriz cultural. Matriz cultural porque serve como mediação na transmissão de conhecimentos, saberes, crenças, sonhos, valores, símbolos e atitudes sociais. As feiras, entendidas enquanto paisagens, apresentam uma faceta funcional e outra simbólica. Funcional porque existem para atender ao consumo das sociedades locais, aspecto que foi abordado anteriormente, e simbólica, porque condiciona e resulta de um conjunto de práticas e tradições construído coletivamente.

Para Cosgrove (1999, pp. 103 e 104) "a maioria das pessoas vive em sociedades que são divididas em classe, casta, sexo, idade ou etnicidade". Essa diferenciação geralmente reflete a divisão territorial e social do trabalho. Para ele uma posição diferenciada na sociedade significa uma experiência e consciência diferentes e, até certo ponto, indica uma cultura diferente. Sendo assim, a maioria dos consumidores que frequenta os mercados periódicos possui experiência e consciência diferenciadas, pois, ao fazer parte de uma classe social de baixo poder aquisitivo ${ }^{3}$, construiu, ao longo do tempo, hábitos, costumes e vivências diferentes, em relação à população que tem maior poder de compra.

A escolha pela aquisição de produtos da feira se constitui num aspecto cultural característico de determinada parcela da população, da mesma forma que a escolha por comprar em lojas de mercados e supermercados corresponde também a hábitos específicos. Não existe um limite rígido, no sentido de mostrar que determinado grupo socioeconômico e cultural compra somente na feira e outro em mercados e supermercados, porém, as relações culturais materializadas na feira (de temporalidade lenta) não são as mesmas que se manifestam no comércio do circuito superior (de temporalidade frenética), por exemplo. As relações culturais ocorridas na feira (e os signos e significados advindos daí) se dão de forma diferente daquelas que se estabelecem nas lojas e em supermercados. Essas relações não podem estar dissociadas da materialidade sobre a qual se dão e, para Cosgrove, não devem ser entendidas de forma estanque sem levar em conta as imbricações do poder entre agentes produtores do comércio no espaço da cidade.

A "disputa" por espaço entre lojas varejistas e as barracas das feiras revela que as manifestações culturais estão intimamente ligadas às relações de poder, logo, há, entre os dois circuitos econômicos (o circuito

3 Conforme resposta de questionário aplicado a 325 frequentadores das cinco feiras livres analisadas, identificou-se que cerca de $25 \%$ deles (exceto os consumidores da feira de Itapetinga) tem rendimento mensal abaixo de um salário mínimo, e mais de $45 \%$ tem rendimento mensal entre um e dois salários mínimos. inferior e superior) (Santos, 1979), relações deste tipo que se revelam na localização e tamanho dos estabelecimentos de compra e venda, no preço dos produtos comercializados e no vínculo entre consumidor e donos de estabelecimentos. Enquanto a pechincha é uma prática/costume herdada do passado, comum entre comprador e vendedor nas primeiras, no supermercado o contato entre esses entes é superficial, e a compra pela caderneta foi substituída pelo cartão de crédito.

Relações de poder também se manifestam no espaço da feira e no seu entorno e se caracterizam pelas ações da esfera pública municipal que planeja, sem participação dos feirantes, intervenções visando à padronização dos pontos de venda e delimitando as áreas onde os diferentes produtos deveriam ser estocados e comercializados. Já nos arredores das feiras, esse poder se expressa nas estratégias criadas pelo comércio formal para atrair o consumidor da feira livre para as suas lojas e supermercados. Em contrapartida, o prestígio dos feirantes se mostra na não-obediência às determinações do poder público municipal, quando ignoram portarias criadas pelas prefeituras definindo taxação semanal e/ou mensal pela utilização dos pontos de venda, ou rebelando-se para não utilizar boxes para venda de seus produtos, optando em comercializá-los na feira livre. Por conta desses conflitos, a análise da feira em sua aparição fenomênica não deve estar desassociada dos estudos sobre as relações de poder, nos quais estão envolvidos agentes múltiplos que as produzem. Na sequência evidenciaremos a dimensão cultural (imaterial) das feiras por meio das experiências pessoais e coletivas e da representação delas para os seus frequentadores.

\section{Dando voz aos agentes produtores da feira: significados e sentimentos sobre o lugar}

Cada indivíduo constrói, ao longo da sua existência, diferentes relações-significados-vivências com os lugares que habita. Uma geografia que dê conta dessa dimensão "procura um entendimento do mundo humano através do estudo das relações das pessoas com a natureza, do seu comportamento geográfico, bem como dos seus sentimentos e ideias a respeito do espaço e do lugar" (Tuan, 1995, p. 143). Esses sentimentos e ideias construídos a partir dessas conexões resultam de experiências espaciais pretéritas e atuais. Desse modo, os significados construídos sobre a paisagem e o lugar, ou seja, construídos sobre as feiras livres de Maiquinique, Macarani, Itarantim, Itororó e Itapetinga, e o hábito de nelas comprarem e venderem produtos, refletem temporalidades diferentes.

Na década de 1970, mais da metade da população total dos cinco municípios (cerca de 54.887 habitantes) residia no espaço rural. Isso nos permite afirmar que a maioria dos consumidores das feiras livres dessas unidades municipais vivia nesse espaço. Essa condição imprimia no 
modus vivendi dessa população relações sociais e de trabalho próprias da roça, mas que continuam resistindo ainda no começo do século XXI, mesmo com a extensão do processo de urbanização no sertão do Brasil.

Como foi apresentado acima, um motivo que ainda continua levando os moradores do campo à feira é a necessidade de venda do excedente agrícola e a obtenção do dinheiro necessário para comprar o que não se produz em suas pequenas propriedades. Entretanto, esse não pode ser entendido como o único motivo de apropriação desse espaço nas cidades contemporâneas e naquelas que estudamos. A feira significa, também para quem a frequenta, o lugar do encontro e, por vezes, a possibilidade de lazer para seus usuários, uma vez que se pode passear pelos corredores entre as barracas, rever parentes ou amigos ou mesmo se deparar com produtos novos, de origem distante.

Famílias inteiras veem também no dia de sábado a possibilidade de se informar dos acontecimentos das localidades mais distantes. "Eu venho à feira para vender farinha, ovos de galinha e também para comprar. Além disso, eu encontro os conhecidos, não é? Ela é bonita, o povo e as coisas também são; é por isso também que eu gosto da feira", afirmou Eliene Bispo do Santos, moradora na Fazenda Água Doce (município de Itororó). Odílio José dos Santos, 47 anos, residente na Fazenda Utinga, município de Maiquinique, frequenta a feira pelos mesmos motivos apresentados acima, porém para ele, ela tem um significado existencial:

Venho à feira vender verdura, cereais e também para comprar carne e pagar alguma prestação. Também aproveito para ver os amigos e para visitar o médico. Somente no sábado é possível fazer tudo isso. Se eu deixo de vir à feira em algum sábado, sinto que falta alguma coisa em mim. Desde pequeno que eu frequento, então, ela faz parte da minha vida.

Odetino José dos Santos, de 66 anos, residente na Fazenda Palmeira, ao relatar sobre o objetivo que o traz à feira disse: "A gente vem para comprar, mas também a gente vem para saber como está a cidade e as novidades da semana". Para Milton José dos Santos, 43 anos, morador da zona rural desse município,

A feira não serve apenas para comprar, a gente aproveita e faz outras coisas. Todo sábado encontro amigos e a gente prosa muito; cada um fica sabendo as coisas novas que acontecem nas outras roças. Às vezes eu aproveito para ir ao hospital pra fazer exames.

Outra feirante-consumidora, Ednália Vieira Oliveira, 39 anos, moradora na zona rural de Itarantim e que frequenta a feira livre deste município, ao ser questionada sobre os motivos que a levariam à feira, afirmou:

[...] tem parente que eu vejo só na feira, então a gente aproveita pra colocar o papo em dia. Às vezes nem compro muita coisa, mas venho à feira para ver esses parentes e também porque ela é muito alegre, movimentada e a gente encontra os amigos também. Quando sobra tempo, também vou à igreja.

Para Patrícia de Jesus Santos, 23 anos, residente na fazenda Córrego d Água, município de Macarani, a ida à feira possibilita ainda ir à casa dos amigos "bater um papo", visitar lojas, fazer exames, arrancar dente e resolver alguns problemas. Ela também visita a feira porque gosta do seu movimento, das pessoas e de suas atitudes. "Além disso, rever os parentes é muito bom", afirmou ela.

Como se observa nas falas descritas acima, são muitos os motivos que influenciam nas relações-significados-vivências dos homens e mulheres a partir das idas às feiras aos sábados. Esses motivos podem ser agrupados em pelo menos três: em primeiro lugar, o mais aludido, que possibilita a apropriação desta fração da cidade, é a compra e a venda de produtos de subsistência. Essa função da feira é um dos condicionantes que possibilita sua permanência no tempo conforme mostrou Bromley, Symansky e Good (1980). Uma segunda razão que alimenta essa prática é a necessidade de preservar a tradição e de manter, por meio da conversa ou da oferta de produtos do campo, as relações de parentesco e de amizade; com os encontros e diálogos entre a visita à uma barraca e outra, os feirantes aproveitam para se inteirarem das notícias que a carta, o rádio e, mais recentemente, a televisão não divulgam. 0 ato de ir à feira é uma necessidade que, se não for atendida, produz uma insatisfação, um desconforto, como expressou um dos entrevistados: pois "[...] o hábito governa a vida das pessoas" (Tuan, 1995, p. 158). E, por fim, o terceiro motivo associa-se à função urbana que as cidades têm para a população rural ao oferecer serviços médico-hospitalares, religiosos, entre outros. Além da possibilidade de frequentar igrejas, a feira em si tem uma representação religiosa para alguns de seus usuários.

Ana Pereira da Silva, de 52 anos, residente na Fazenda Rio Pardo (município de Macarani) associa a existência da feira à presença divina: "Além de vir aqui para comprar e vender, também venho prosar com os amigos e sentir a presença de Deus. O que eu mais gosto na feira é dessa presença”. Já para Edivaldo Ferreira de Oliveira, 42 anos, domiciliado na sede do município de Itapetinga, a visita à feira possibilita a comunhão:

Nós queremos estar perto de outras pessoas, dar e receber carinho. Ver o povo unido na feira é algo muito bonito. As pessoas aqui são muito educadas e hoje a primeira coisa que você tem que ter é educação; é uma pena que a feira está um pouco devagar de uns tempos pra cá.

Esses dois últimos relatos mostram o valor simbólico que a feira possui para uma parte dos que a frequentam. Ao afirmar que o que mais se gosta naquele espaço é a presença de uma determinada divindade, a feirante a vê como um lugar onde se manifesta uma força superior. 0 significado divino a ela dado pode se relacionar ao fato de que, em mui- 
tos centros de peregrinação religiosa no interior do Brasil, as feiras livres fazem parte da paisagem e, geralmente se localizam nas proximidades de objetos geográficos de visitação (igrejas, estátuas, monumentos, grutas, etc.). Considerando a narrativa do último entrevistado, a feira possui um aspecto diferenciado de outros espaços da cidade. 0 encontro, a conversa e a coletividade manifestam-se em toda sua extensão, de maneira que seus utentes se sentam construtores desse acontecer, marcado pela solidariedade na medida em que são compartilhados projetos, alegrias, tristezas e acontecimentos da vida cotidiana.

Sendo assim, pode-se auferir que a rotina de ir à feira possui diferentes significados, que refletem relações sociais prenhes de afetividade, de valores e marcadas por necessidades materiais e imateriais das comunidades envolvidas, mostrando, assim, que há concordância entre as crenças e os valores dos feirantes e suas atitudes. Para a população que habitava a zona rural e que migrou para a cidade, a feira continua sendo o "lugar da modernidade", mas também o espaço do encontro com símbolos do campo e com campesinos que lá continuam residindo. Esses significados clarificam a discussão apresentada sobre o conteúdo cultural (e das relações de poder) presente nos mercados periódicos, cuja periodização e aparência reflete sua função econômica e simbólica.

\section{Considerações finais}

A feira livre é uma atividade econômica, social e cultural secular presente nas sociedades espalhadas por diferentes regiões do Brasil e do mundo.
De acordo com os autores que dialogamos, elas surgem em sociedades marcadas por diferenças de classe, casta, sexo, idade ou étnicas e continuam existindo em função da necessidade de compra e venda, em função da inércia e da organização do tempo semanal. É um fenômeno cultural porque vem sendo transmitido de geração em geração, se manifesta na paisagem e possui conteúdo simbólico.

Discutimos, neste trabalho, que a dinâmica da feira se diferencia daquela que ocorre no interior das lojas de mercados e supermercados; as disputas entre uma cultura resistente e uma cultura dominante revelam que a presença e permanência da feira livre na cidade contemporânea são marcadas por conflitos e relações de poder. No entanto, acredita-se que sua função e os significados que possui para a população que a frequenta se constituem em elementos que manterão sua territorialidade frente às mudanças que vêm ocorrendo nos circuitos de produção, venda e consumo de mercadorias na atualidade.

Procurou-se também interpretar a experiência humana materializada nos mercados periódicos em seus significados e símbolos como parte da paisagem e do lugar na sociedade que se desenvolve no interior do Brasil. A paisagem foi desvelada em sua dimensão cultural e de resistência e lugar entendido como relações-significados-vivências compartilhados. Essa interpretação somente foi possível graças às vozes, aos ditos (e aos não ditos) daqueles que fazem da feira livre um espaço público no qual se desenvolvem relações sociais prenhes de afetividade. 


\section{Referências}

Bromley, R. J.; Symanski, R., \& Good, C. M., (1980). Análise racional dos mercados periódicos. Revista Brasileira de Geografia, 42 (1), p. 183-94.

Corrêa, R. L., (1995). A dimensão cultural do espaço: alguns temas. : Espaço e Cultura, 1. p. 1-22.

(2014). Carl Sauer e Denis Cosgrove: a paisagem e o passado. Espaço Aberto, 4 (1), p. 37-46.

Cosgrove, D., (1999). A cultura está em toda parte. Em: Z. Rosendahl \& R. Corrêa, (Orgs.). Manifestações da Cultura no Espaço (pp. 92-123). Rio de Janeiro: Eduerj.

Porto, G. C., (2005). Configuração Sócio-espacial e Inserção das feiras livres de Itapetinga-Ba e arredores no circuito inferior da economia. Dissertação de Mestrado em Geografia. Universidade Federal da Bahia, Instituto de Geociências., Salvador, BA, Brasil..

., (2007). Circuito inferior da economia urbana: o contexto das feiras livres de Itapetinga (BA) e arredores Anales del XI Encuentro de Geógrafos de América Latina. 2007. Bogotá, Colombia..

Santos, M., (1979). O espaço dividido: os dois circuitos da economia dos países subdesenvolvidos. Rio de Janeiro: F. Alves.

Tuan, Y.F., (1995) Geografia humanística. Em: A. Christofoletti (Org.) Perspectivas da Geografia (pp. 143-164). São Paulo: Difel. 